\title{
$\alpha$-mangostin preserves hepatic microvascular architecture in fibrotic rats as shown by scanning electron microscopy of vascular corrosion casts
}

\author{
WASAN TANGPHOKHANON $^{1}$, WISUIT PRADIDARCHEEP ${ }^{2}$ and ALOIS LAMETSCHWANDTNER ${ }^{3}$ \\ ${ }^{1}$ Center of Excellence in Veterinary Biosciences, Department of Veterinary Biosciences and Public Health, \\ Faculty of Veterinary Medicine, Chiang Mai University, Chiang Mai 50100; \\ ${ }^{2}$ Department of Anatomy, Faculty of Medicine, Srinakharinwirot University, Bangkok 10110, Thailand; \\ ${ }^{3}$ Department of Biosciences, Vascular and Exercise Biology Unit, University of Salzburg, Salzburg 5020, Austria
}

Received November 6, 2020; Accepted March 4, 2021

DOI: 10.3892/br.2021.1424

\begin{abstract}
Liver fibrosis is a dynamic condition caused by wound-healing in which scar tissue replaces the liver parenchyma following repetitive injuries. It is hypothesized that $\alpha$-mangostin (AM), the major constituent of the xanthone fraction in extracts of Garcinia mangostana L., may protect the hepatic microvascular bed from thioacetamide (TAA)-induced fibrosis. In the present study, rats were divided into 4 groups: Control rats received no treatment; TAA-treated rats received $150 \mathrm{mg} / \mathrm{kg}$ TAA 3 times per week intraperitoneally; AM-treated rats received $75 \mathrm{mg} / \mathrm{kg}$ AM twice per week intraperitoneally; and TAA+AM-treated rats received both TAA and AM as described above. Rat livers were processed either for light microscopy or for vascular corrosion casting after 30 and 60 days of treatment. Vascular parameters were measured by $3 \mathrm{D}$ morphometry analysis of scanning electron micrographs. AM attenuated hepatocellular injuries and delayed both periportal and pericentral fibrosis in the TAA-treated rats. The comparison of findings at day 30 and 60 showed that TAA-induced fibrotic changes were progressive in time, and that the beneficial effects of AM only became apparent after prolonged treatment. The livers of rats treated with both TAA and AM had less space surrounding the portal vessels, improved preservation of the hepatic microvascular pattern, and minimally altered sinusoidal patterns with few signs of terminal portal venule remodeling. AM therefore partially protected the liver against hepatotoxin-induced fibrosis and the associated microvascular changes. The mechanism of the protective effect of AM on the liver remains to be investigated.
\end{abstract}

Correspondence to: Dr Wasan Tangphokhanon, Center of Excellence in Veterinary Biosciences, Department of Veterinary Biosciences and Public Health, Faculty of Veterinary Medicine, Building D, Chiang Mai University, Chonprathan Road, Chiang Mai 50100, Thailand

E-mail: wasan.tangphokhanon@cmu.ac.th

Key words: $\alpha$-mangostin, fibrosis, hepatic vessels, microvascular casting, 3D morphometry

\section{Introduction}

Liver fibrosis is a dynamic wound-healing process in which scar tissue replaces liver parenchyma as a result of repetitive liver injuries (1). Persisting liver injury due to various factors, such as chronic inflammation and progressive fibrogenesis, may lead to cirrhosis (2). The liver is supplied by poorly oxygenated venous blood via the portal vein, whereas the well oxygenated blood is supplied by the hepatic artery (3). Hepatic microvascular structures consist of two types of vessels: The larger vessels (such as the hepatic portal venule and hepatic arterioles) are lined by continuous endothelium, whereas the smaller sinusoids are lined by fenestrated endothelium. The central venules drain the sinusoids and, in turn, combine to form the hepatic veins (4). Fibrous tissue hinders the flow of blood through the liver, which in turn results in abnormal liver function (5-7).

Angiogenesis is the process of formation of new blood vessels from pre-existing vessels. Vessel formation can occur by sprouting angiogenesis or a process of vessel splitting known as intussusceptive angiogenesis (IA) (8). Angiogenesis is crucial in both normal development and pathological conditions, such as wound healing (9).

Cirrhosis is one of the most common diseases in humans $(10,11)$ and animals, such as dogs (12-14) and horses (15). This disease is not yet curable, and treatments are usually focused on preventing its progress (16). Only few established antifibrotic drugs are available, which are primarily used for fibrosis in the lungs or skin (17). Some natural products may however possess hepatoprotective effects. The bark of Butea monosperma can at least partially reverse changes in markers associated with fibrosis to normal and inhibit thioacetamide (TAA)-induced expression of phosphorylated PI3K, Akt and mTOR in hepatocytes (18). Justicia tranquebariesis extract enhances the activities of antioxidant enzymes in TAA-induced liver fibrosis in rats (19). Curcumin extract attenuates fibrosis and decreases inflammation in rats (20).

Extracts of purple mangosteen (Garcinia mangostana L.) are rich in xanthones, which inhibit some of the CytP450 isoenzymes and possess antifungal activity $(21,22)$. 
Furthermore, such extracts inhibit tumor growth in vitro (23). Previously, $\alpha$-mangostin [1,3,6-trihydroxy-7-methoxy-2,8-bis (3-methyl-2-butenyl)-9H-xanthen-9-one; $\mathrm{C}_{24} \mathrm{H}_{26} \mathrm{O}_{6} ; \mathrm{AM}$, which is the major constituent in the polyphenolic xanthone fractions of Garcinia mangostana L. extracts, have been investigated in vitro for its antioxidant (24-27), anti-bacterial $(28,29)$, anti-inflammatory $(30-32)$, anti-fibrotic $(33)$, anti-cancer (34-40) and anti-angiogenic activitie (41). Whether AM has beneficial effects in vivo on fibrotic livers has not yet been investigated.

The focus of the present study was to establish whether AM possessed protective effects on the hepatic micro-angio-architecture in TAA-induced fibrosis in rats in vivo. Hepatic histomorphology and micro-angio-architecture were assessed both qualitatively and quantitatively in vascular corrosion casts (VCCs) using a scanning electron microscope (SEM) and 3D morphometry of the VCCs. It was hypothesized that AM treatment would prevent or mitigate the appearance of pathological changes in the hepatic micro-angio-architecture of the TAA-treated rats.

\section{Materials and methods}

Animals and reagents. A total of 40 male Wistar rats, aged between 4-5 weeks and weighing between 130-160 grams, were purchased from the National Laboratory Animal Center, Mahidol University, Thailand. Rats were provided ad libitum access to water and commercial food pellets, and were housed in ordinary cages at room temperature $\left(25^{\circ} \mathrm{C}\right)$, with a relative humidity of 50\%, and a $12 \mathrm{~h} \mathrm{light/dark} \mathrm{cycle.} \mathrm{Rats} \mathrm{were} \mathrm{treated}$ in accordance with the guidelines described in the Guide for the Care and Use of Laboratory Animals (42). All of the experiments were approved by the Institutional Animal Care and Use Committee at the Faculty of Veterinary Medicine, Chiang Mai University (approval no. A.20/2555). Animal behavior and welfare were monitored weekly, and this included: i) Behavior (feeding, grooming and responsive reactions); ii) rat grimace scale for assessing the occurrence or severity of pain; and iii) weekly weight loss percentage.

AM (96\% pure) was received from Dr Primchanien Moongkarndi, Department of Microbiology, Faculty of Pharmacy, Mahidol University. Mangosteen fruits, Garcinia mangostana L. (Clusiaceae), were harvested in the Chanthaburi Province, Thailand. The plant was authenticated by Dr Omboon Vallisuta, Department of Pharmacognosy, Mahidol University, Thailand (voucher specimen no. WGM0615). Preparation, extraction and purification of AM were performed as described previously $(43,44)$. TAA ( $\geq 99.0 \%$ pure) was purchased from Sigma-Aldrich; Merck KGaA; cat. no. 163678).

Experimental design. After 1 week of acclimatization, rats were randomly divided into 4 groups ( $n=10$ per group; Fig. 1): The control group (Ctrl) was injected intraperitoneally with $0.9 \%$ normal saline solution (NSS) 3 times per week. The TAA group was injected with $150 \mathrm{mg}$ TAA/kg body weight (BW) intraperitoneally 3 times per week to induce liver fibrosis (45). The AM group was injected with $75 \mathrm{mg} \mathrm{AM} / \mathrm{kg} \mathrm{BW}$ intraperitoneally twice per week. The TAA+AM group was injected with $150 \mathrm{mg}$ TAA $/ \mathrm{kg}$ BW intraperitoneally 3 times per week plus $75 \mathrm{mg} \mathrm{AM} / \mathrm{kg}$ BW intraperitoneally twice per week. A total of 5 rats per a group were treated for 30 days and the other 5 were treated for 60 days. In each subgroup, 2 rats were processed for light microscopy analysis and 3 rats for VCC. The treatment regimen was adopted from Poonkhum et al (46), but the dosage of TAA and AM was $75 \%$ of that administered by Poonkhum et al.

VCCs. Rats underwent non-recovery anesthesia by intraperitoneal injection of $60 \mathrm{mg}$ pentobarbital sodium $/ \mathrm{kg}$ BW (NEMBUTAL ${ }^{\circledR}$ Sodium Solution for injection). VCC was performed as described previously (47). Briefly, after opening the thoracic wall, a blunt needle $(18 \mathrm{G})$ was inserted into the thoracic aorta and fixed, then the blood samples were collected. After opening the right atrium, circulating blood was rinsed out by perfusion with $200 \mathrm{ml} \mathrm{NSS}$ containing heparin $(5,000 \mathrm{IU} / \mathrm{l})$. Rats died shortly after when a clear reflux emerged from the opened right atrium. Vital signs were re-evaluated and death was confirmed by lack of vital signs observed (no response to withdrawal reflex in all limbs, no deep pain and lack of heart beat, heart rate and breathing). Next, $20 \mathrm{ml}$ Mercox-Cl-2B (cat. no. 21246; Ladd Research, Inc.) mixed with $0.4 \mathrm{~g}$ Benzoyl Peroxide (catalyst for Mercox; cat. no. 21246A; Ladd Research, Inc.) was injected at a constant flow rate of $4 \mathrm{ml} / \mathrm{min}$ via an auto-syringe pump (Terumo model TE 311; Terumo Corporation). After keeping the specimens for at least $30 \mathrm{~min}$ at room temperature to allow polymerization, animals were transferred into a water bath at $60^{\circ} \mathrm{C}$ for $12 \mathrm{~h}$ to further harden the cast. Thereafter, animals were transferred into a solution of $1.34 \mathrm{~mol} / \mathrm{l} \mathrm{KOH}$ for at least $12 \mathrm{~h}\left(40^{\circ} \mathrm{C}\right)$, rinsed in up to three passages of distilled water, and then submerged in a solution of $1.33 \mathrm{~mol} / 1$ formic acid $\left(\mathrm{CH}_{2} \mathrm{O}_{2} ; 5-10 \mathrm{~min}\right.$ at room temperature) to remove any tissue remnants adhering to the cast surfaces. Finally, VCCs were rinsed in several passages of distilled water, and air-dried. Dissected dry specimens comprising most of the liver were mounted on copper stubs, using the conductive bridge method (48), and coated with evaporated carbon (using the electric arc method) and gold (by resistive heating under a high vacuum of a minimum of $1 \times 10^{-4}$ mbar) using a vacuum evaporator (EPA 100; Leybold-Hereaus). Coated specimens were assessed using a SEM (Phillips ESEM XL30 FEI; Philips Medical Systems B.V.) at an accelerating voltage of $10 \mathrm{kV}$, and images were captured using Orion version 6.60.4 (E.L.I. s.p.r.l.) at magnifications of $x 150, x 251, x 1,000$ and x1,500. Specimens were repeatedly trimmed manually using micro-dissection forceps and scissors to expose interesting vascular territories.

Tissue preparation for histomorphology. Preparatory steps and blood sample collection were performed as described in the VCCs section above. Vascular perfusions from the thoracic aorta were performed once the perfusate from the opened right atrium did not contain erythrocytes. Then, $20 \mathrm{ml} 4 \%$ formaldehyde in PBS was injected with an infusion pump $(40 \mathrm{ml} / \mathrm{h})$. After fixing for $1 \mathrm{~h}$ at $25^{\circ} \mathrm{C}$, the abdominal cavity was opened, the liver was excised and fixed for a further $12-24 \mathrm{~h}$ in fresh fixative at $4^{\circ} \mathrm{C}$. The entire liver was then dehydrated in an ascending series of graded ethanol solutions and embedded in paraplast (Surgipath ${ }^{\mathrm{TM}}$ Paraplast $^{\mathrm{TM}}$; Leica Microsystems, Inc.). The embedded livers were sectioned into $7 \mu \mathrm{m}$ thick sections, which were stained with hematoxylin and eosin (H\&E). Tissues were first stained in hematoxylin solution for $6 \mathrm{~min}$ 

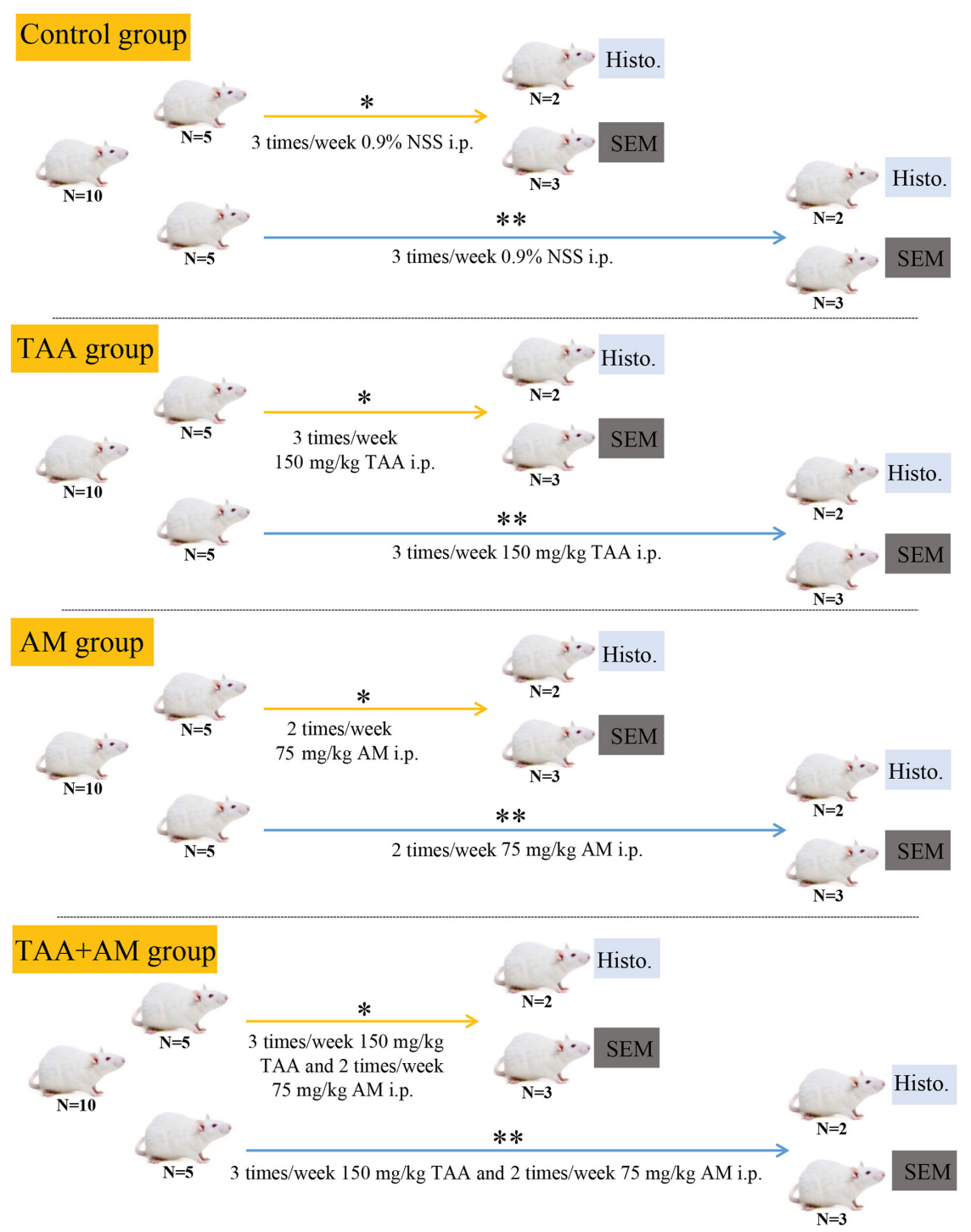

Figure 1. Schematic diagram of the experimental design. AM, $\alpha$-mangostin; TAA, thioacetamide; SEM, scanning electron microscopy; Histo. Histological staining with hematoxylin and eosin or Sirius red. "Rats treated for 30 days; ${ }^{* *}$ Rats treated for 60 days.

then counterstained in eosin solution for $1 \mathrm{~min}$ at $25^{\circ} \mathrm{C}$. The presence of collagen fibers (fibrosis) was visualized by staining with Sirius red for $1 \mathrm{~h}$ at $25^{\circ} \mathrm{C}$ (Direct Red 80; cat. no. 365548; Sigma-Aldrich; Merck KGaA). The Ishak scoring system was used to measure activity and fibrosis, rating the different elements of activity as either present or absent, ranging from 0 to 6 , with a higher score reflecting increased scarring (49), by consensus between 2 experts.

All slides were scanned with a digital slide scanner (Panoramic SCAN II; 3DHISTECH, Ltd.). Micrographs were captured and exported to CaseViewer version 2.4. (3DHISTECH, Ltd.)

Liver enzyme markers. Following induction of deep anesthesia, blood samples collected from the thoracic aorta during VCCs and tissue preparation for histomorphology steps at day 30 and day 60 were submitted to the Animal Health Diagnostic Laboratory, Faculty of Veterinary Medicine, Chiang Mai University. Serum alanine aminotransferase (ALT) and aspartate aminotransferase (AST) activities were assessed using optimized UV-tests $(50,51)$, alkaline phosphatase (ALP) activities were assessed using a kinetic photometric test (52) as described by the International Federation of Clinical Chemistry and Laboratory Medicine.

Microstructure description and quantitative analyses. Differences in the microstructure of the liver between groups were analyzed in a descriptive manner by consensus between 2 experts. Information regarding dimensional changes of the hepatic microvascular network, including diameters of venous vessels and hepatic sinusoids, and branching angles of venous vessels and sinusoids were measured from stereo-paired SEM-micrographs of VCC of the liver by 3D-morphometry $(53,54)$ using the M3 software (Microstructure Morphometry Measurement Tool version 2.2 (ComServ). The geometry of microvascular trees in terms of spatial coordinates and derived distance, as well as angular measurements in 3D space were calculated from two sets of planar coordinates obtained from the stereopairs using the parallax and considering the type of projection in the SEM by trigonometric vector equation-based algorithms; for further details on dimensional and angular measurement calculations please see Minnich et al (54). 

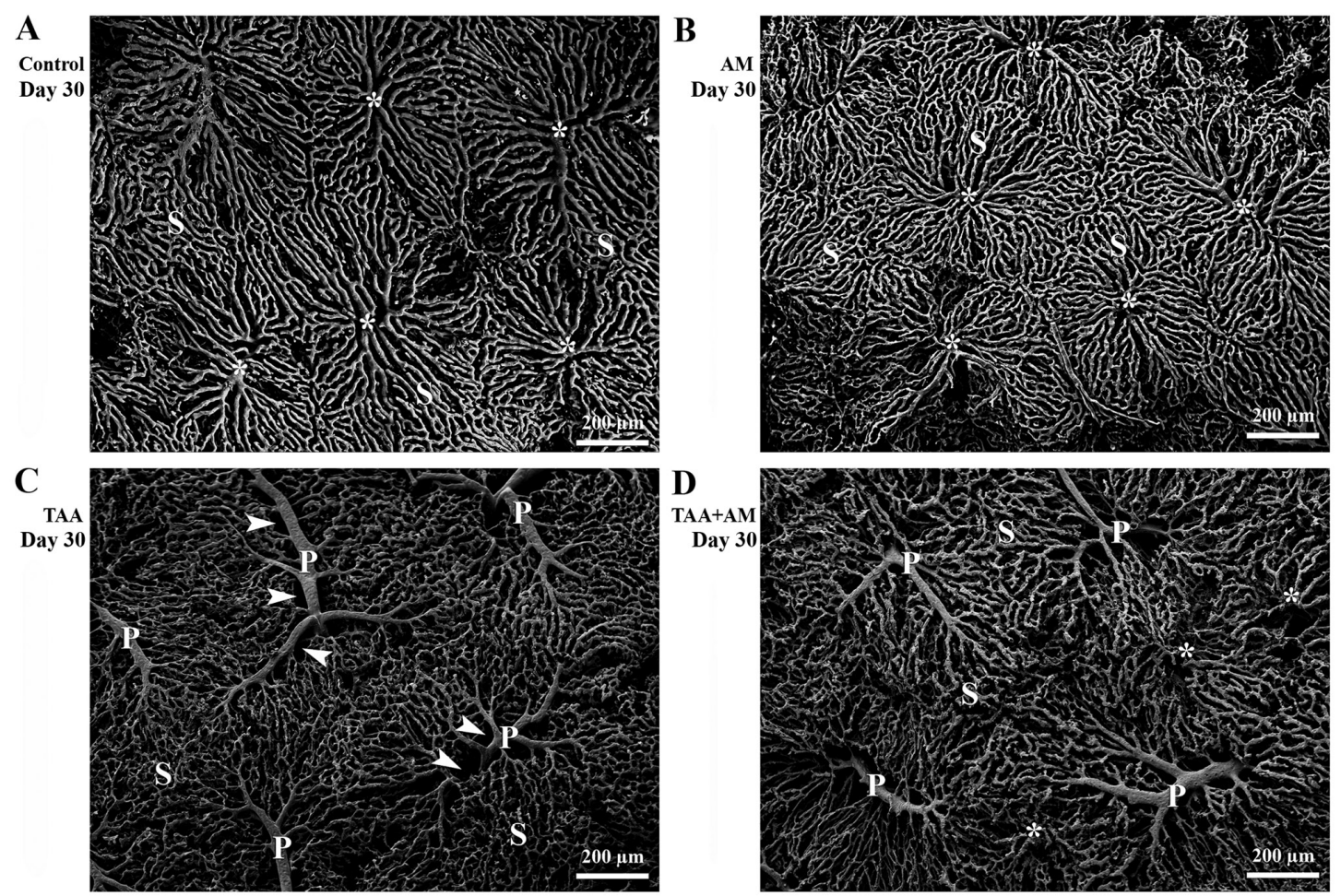

Figure 2. Vascular corrosion casts of the livers of the treated Wistar rats. Surface view after 30 days of treatment. Asterisks mark terminal hepatic venules, whereas arrowheads mark space surrounding portal venules (denoted by P) and sinusoids (denoted by S). Scale bar, $200 \mu \mathrm{m}$. (A) Overview of the hepatic microvascular architecture in the control rats. (B) AM treatment did not change the microvascular architecture. (C) TAA treatment modified the microvascular architecture, as observed by the increased space (arrowheads) around the portal vessels. (D) Addition of $\alpha$-mangostin to thioacetamide treatment reveals portal venules, terminal hepatic venules and microvascular changes similar to panel C. AM, $\alpha$-mangostin; TAA, thioacetamide.

Statistical analysis. Quantitative data (diameters of venous vessels and hepatic sinusoids, and branching angles of venous vessels and sinusoids) were analyzed using a one-way ANOVA. A two-way ANOVA was used to analyze the differences between the different groups (control, AM, TAA, and TAA+AM) and time period (at day 30 and day 60), including the interaction between the different groups and time periods. Post hoc analyses were performed following one and two-way ANOVA using Bonferroni corrections. Data were analyzed using SPSS version 26.0 (IBM Corp.). $\mathrm{P}<0.05$ was considered to indicate a statistically significant difference.

\section{Results}

Body weight. Differences in body weight were observed. After 30 days of exposure, there was a decreased body weight in the AM, TAA and TAA+AM-treated rats compared with the control rats and an increase in the liver-to-body weight ratio in the TAA-treated rats. After 60 days of exposure, there was a decrease in body weight in the TAA and TAA+AM-treated rats compared with the control rats. There was a statistically significant difference in the mean body weight between day 30 and day 60 in all treatment groups (Table I). All rats behaved normally and showed no noticeable undesired effects following the TAA or AM treatment.

Liver enzyme markers. The serum transaminases levels were similar in the control and AM-treated rats, except for an increased ALP concentration in the AM-treated rats after 60 days of treatment compared with the control rats. The serum levels of AST, ALT and ALP in the TAA-treated rats after 60 days of treatment were significantly increased compared with the control rats, but additional treatment with AM (TAA+AM-treated rats) normalized these values after both 30 and 60 days of treatment (Table II).

VVCs. After 30 days of treatment, the surface of the VCCs of the control rats (Fig. 2A) revealed a normal hepatic microvascular architecture. The sinusoids (denoted with an S) were arranged in a distinct continuous pattern, had a constant diameter, and were typically arranged into lobular units. The sinusoidal blood drained into central veins (denoted with asterisks). The sinusoidal network of AM-treated rats (Fig. 2B) resembled that of the control rats. The livers of the TAA-treated rats (Fig. 2C) displayed a modified sinusoidal arrangement, with replacement of the lobular structures with acinar structures and considerable space (arrowhead) around the portal vessels (denoted with a P). The livers of the TAA+AM-treated rats showed changes in the portal vessels and sinusoidal patterns that resembled that of the TAA-treated rats (Fig. 2D).

After 60 days of treatment, the superficial microvascular pattern in the control rats (Fig. 3A) was similar to that of the controls after 30 days. Portal vessels were well developed in the livers of AM-treated rats and the microvascular architecture changed only slightly (Fig. 3B). Significant and progressive changes in the sinusoidal patterns were found in the liver of the TAA-treated rats, with substantial space around the portal vessels (arrowheads; Fig. 3C). Pericentral sinusoids were smaller and more closely packed, which led to micro-nodule formation (denoted with an $\mathrm{N}$ ). In addition, 
Table I. Body weight, liver weight and liver-to-body weight ratio in the control in the treated rats ${ }^{\mathrm{a}}$.

A, Day 30

\begin{tabular}{lcccc}
\hline & \multicolumn{3}{c}{ Groups } \\
\cline { 2 - 5 } Parameter & Control & AM & TAA & TAA+AM \\
\hline Body weight, g & $487.5 \pm 15.54$ & $427.7 \pm 13.55^{\mathrm{c}}$ & $401.0 \pm 6.83^{\mathrm{b}}$ & $401.8 \pm 6.37^{\mathrm{c}}$ \\
Liver weight, $\mathrm{g}$ & $20.1 \pm 0.8$ & $19.5 \pm 0.4$ & $18.7 \pm 0.6$ & $18.0 \pm 0.70$ \\
Liver-to-body weight ratio, $\%$ & $3.99 \pm 0.03$ & $4.29 \pm 0.09$ & $4.58 \pm 0.08^{\mathrm{b}}$ & $4.34 \pm 0.06$ \\
\hline
\end{tabular}

B, Day 60

\begin{tabular}{lcccc}
\hline & \multicolumn{3}{c}{ Groups } \\
\cline { 2 - 5 } Parameter & Control & AM & TAA & TAA+AM \\
\hline Body weight, g & $581.1 \pm 1.2^{\mathrm{e}}$ & $578.2 \pm 1.0^{\mathrm{e}}$ & $456.0 \pm 9.7^{\mathrm{c}, \mathrm{e}}$ & $501.1 \pm 13.14^{\mathrm{c}, \mathrm{e}}$ \\
Liver weight, g & $23.0 \pm 0.07$ & $23.1 \pm 0.25^{\mathrm{e}}$ & $25.0 \pm 0.7^{\mathrm{e}}$ & $21.2 \pm 0.3^{\mathrm{d}}$ \\
Liver-to-body weight ratio, $\%$ & $4.10 \pm 0.01$ & $4.47 \pm 0.48$ & $5.25 \pm 0.07$ & $4.13 \pm 0.03$ \\
\hline
\end{tabular}

${ }^{a}$ Data are presented as the mean \pm standard deviation; ${ }^{b} \mathrm{P}<0.001$ and ${ }^{\mathrm{C}} \mathrm{P}<0.0001$ vs. respective Control group; ${ }^{\mathrm{d}} \mathrm{P}<0.001$ vs. respective TAA control group; ${ }^{\mathrm{e}} \mathrm{P}<0.001$, significant difference between day 30 and day 60 according to 2-way ANOVA with Bonferroni's corrections. AM, $\alpha$-mangostin; TAA, thioacetamide.

Table II. Serum concentrations of AST, ALT and ALP in the treated rats ${ }^{\mathrm{a}}$.

A, Day 30

\begin{tabular}{lrrrr}
\hline & \multicolumn{3}{c}{ Groups } \\
\cline { 2 - 5 } Parameter & Control & AM & TAA & TAA+AM \\
\hline AST, U/1 & $100.50 \pm 4.50$ & $115.50 \pm 20.50$ & $207.50 \pm 10.50$ & $121.50 \pm 5.50$ \\
ALT, U/1 & $40.00 \pm 2.00$ & $26.00 \pm 43.00$ & $39.00 \pm 14.00$ & $28.50 \pm 2.50$ \\
ALP, U/1 & $74.50 \pm 11.50$ & $83.50 \pm 1.50$ & $160.00 \pm 3.00^{\mathrm{d}}$ & $104.50 \pm 5.50^{\mathrm{e}}$ \\
\hline
\end{tabular}

B, Day 60

\begin{tabular}{lcccr}
\hline & \multicolumn{3}{c}{ Groups } \\
\cline { 2 - 5 } Parameter & Control & AM & TAA & TAA+AM \\
\hline AST, U/l & $117.50 \pm 22.50$ & $191.50 \pm 5.50$ & $364.00 \pm 53.00^{\mathrm{b}}$ & $154.50 \pm 6.36^{\mathrm{e}}$ \\
ALT, U/1 & $41.00 \pm 12.00$ & $32.00 \pm 50.50$ & $198.50 \pm 6.0^{\mathrm{b}}$ & $31.00 \pm 12.00^{\mathrm{e}}$ \\
ALP, U/1 & $80.00 \pm 5.00$ & $153.50 \pm 12.50^{\mathrm{c}}$ & $233.00 \pm 9.00^{\mathrm{d}}$ & $105.50 \pm 10.50^{\mathrm{f}}$
\end{tabular}

${ }^{\text {aD }}$ ata are presented as the mean \pm standard deviation; ${ }^{b} \mathrm{P}<0.01,{ }^{\mathrm{c}} \mathrm{P}<0.001$ and ${ }^{\mathrm{d}} \mathrm{P}<0.0001$ vs. respective Control group; ${ }^{\text {e }}<0.01$ and ${ }^{\mathrm{f}} \mathrm{P}<0.001$ vs. respective TAA group using a 2-way ANOVA with Bonferroni's corrections. AST, aspartate transaminase; ALT, alanine transaminase; ALP, alkaline phosphatase; AM, $\alpha$-mangostin; TAA, thioacetamide.

tiny holes in the terminal portal venules near their branching point were observed. In contrast, the livers of rats treated with both TAA and AM had less space surrounding the portal vessels (Fig. 3D), improved preserved hepatic microvascular patterns, and minimally changed sinusoidal patterns with few signs of terminal portal venule remodeling. Thus, TAA and
AM treatment partially preserved the hepatic microvascular architecture. The terminal portal venules of the TAA and TAA+AM-treated rats after 30 (Fig. 2C and D), and those in the AM, TAA and TAA+AM-treated rats after 60 days of treatment (Fig. 3B-D) could be followed over a long distance, whereas those in the control and AM-treated rats at 


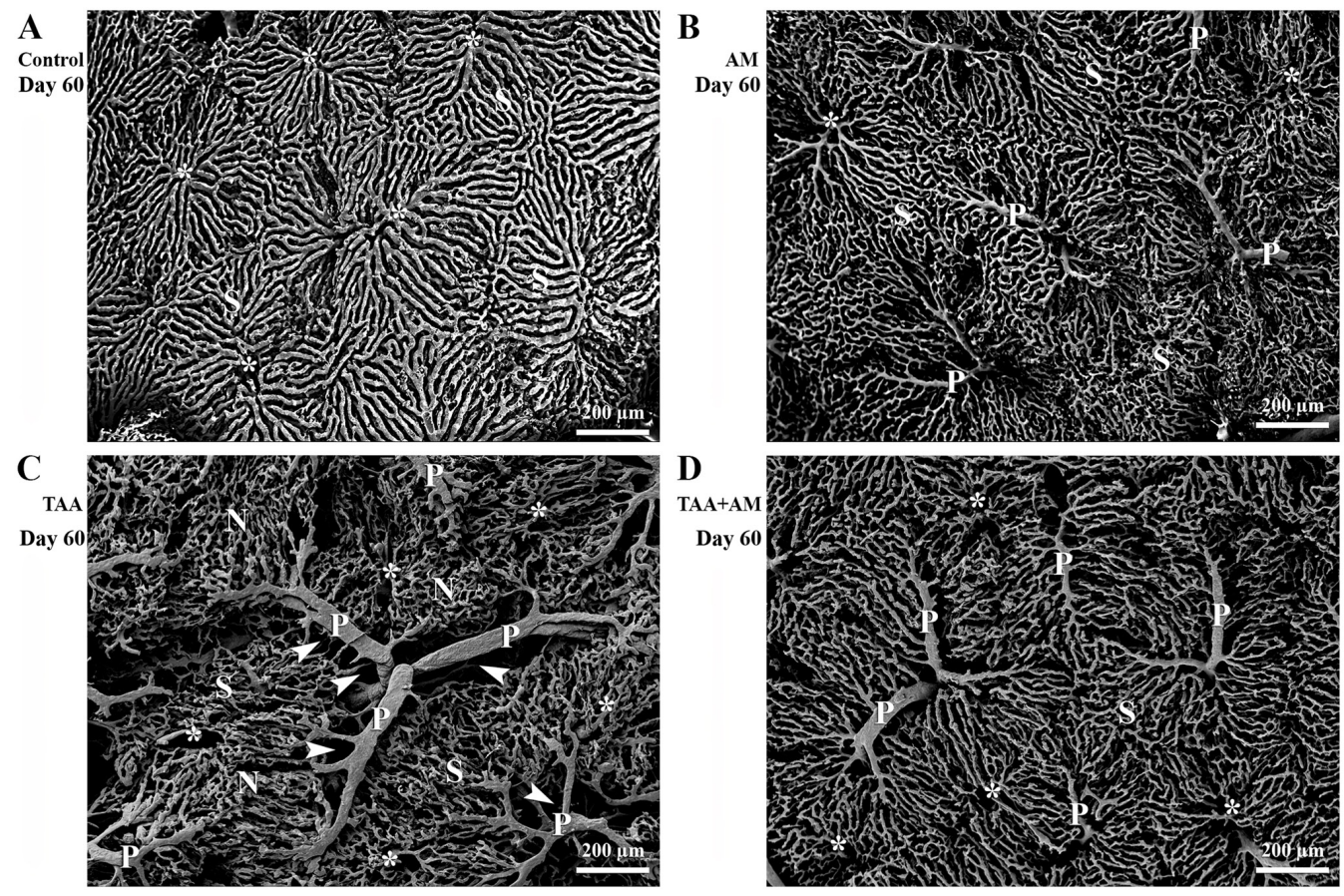

Figure 3. Surface view of the vascular corrosion casts of livers of the treated Wistar rats after 60 days of treatment. Asterisks mark terminal hepatic venules, whereas arrowheads mark the space surrounding portal venules (denoted by P), nodules (denoted by N), and sinusoids. (denoted by S). Scale bar, $200 \mu \mathrm{m}$. (A) Overview of the hepatic microvascular architecture of control rats. (B) AM treatment slightly altered the microvascular architecture. (C) TAA treatment for 60 days resulted in further changes in the microvascular architecture compared with 30 days of treatment, with several large spaces present around the portal vessels. Hepatic nodules are recognizable by their condensed sinusoids and deformed hepatic microvascular architecture. (D) TAA and AM treatment halted further deterioration of the hepatic microvascular architecture compared with 30 days of the combined treatment. AM, $\alpha$-mangostin; TAA, thioacetamide.

day 30 (Fig. 2A and B) and control rats after day 60 (Fig. 3A) were covered entirely by sinusoids.

At higher magnifications, the VCCs clearly revealed that new vessels formed from the original vessel by splitting, which is termed IA. IA was visible as smooth-edged tiny holes with a diameter of $<5 \mu \mathrm{m}$ in the VCCs. Tiny holes were frequently observed in the pericentral area in the control rats (arrows; Fig. 4A) and rats treated with AM for 30 days (arrows; Fig. 4B), which suggested ongoing sinusoidal formation. In addition, tiny holes arranged in a row were seen on portal venules of TAA-treated rats after 30 days (arrows; Fig. 4C), which indicated that the vascular pruning process subsequently finally led to splitting of an existing blood vessel. IA at the branching angle of portal venules and sinusoids in the TAA+AM treated livers (arrows; Fig. 4D). After 60 days, IA was also observed in the periportal sinusoids of the control and AM-treated rats (Fig. 4E and F). Tiny holes in the terminal portal venules near their branching points suggested that an active branching and remodeling process eventually modified the branching angle and resulted in sinusoidal hemodynamic changes (Fig. 4G and $\mathrm{H}$ ). The comparison of findings after 30 and 60 days of treatment revealed that TAA-induced fibrotic changes were progressive in time, and that the beneficial effects of AM only became visible after prolonged treatment, as is shown by comparison of Figs. 2D and 3D.

Histomorphology. Fig. 5A shows an H\&E-stained section of control liver parenchyma, which exhibited a normal lobular architecture containing central or terminal hepatic venules (denoted by asterisks) and portal tracts. The livers of the AM-treated rats (Fig. 5B) did not differ from the control livers, with normal hepatic cords and intact portal structures. Livers of the TAA-treated rats showed acute hepatocellular injury, lobular necrosis with minimal to absent necroinflammatory changes (Fig. 5C). Cellular injury and inflammatory changes in zones 2 and 3, but preserved portal structures were observed in the livers of the TAA+AM-treated rats (Fig. 5D). Fig. 5E and F show higher magnifications of the portal tract, with a hepatic artery (denoted by A), a bile duct (denoted by Bd), a lymph vessel (denoted by Lv) and a portal venule (denoted by P) in a control and an AM-treated animal. The periportal area of the TAA-treated rats (Fig. 5G) showed hepatocyte destruction, whereas various degrees of hydropic changes were also seen in several hepatocytes. Fig. $5 \mathrm{H}$ showed only minimal periportal hepatocyte injury in the TAA+AM-treated rats. Fibrosis was noticeable in periportal and perivenular areas of the TAA-treated rats (Fig. 6C), but was markedly attenuated in the TAA+AM-treated rats (Fig. 6D).

Liver parenchyma of the control rats at 60 days (Fig. 7A) was similar to that of the control rats at 30 days. AM-treatment (Fig. 7B) did not affect liver morphology and showed normal hepatic plates and portal structures. TAA treatment for 60 days caused fibrotic hepatocellular necroinflammatory changes (Fig. 7C). By comparison, the livers of the TAA+AM-treated rats revealed only mild hepatocellular injury (Fig. 7D). At higher magnifications, the portal tract of the control and AM-treated rats (Fig. 7E and F) showed a normal configuration. Fibrosis with prominent periportal and perivenular inflammatory activity and hepatocytes with microvesicular steatosis and cholestasis (arrowhead; Fig. 7G) was present in the livers of rats treated with TAA for 60 days. Additionally, there was no evidence of steatosis or cholestasis, but perivenular 


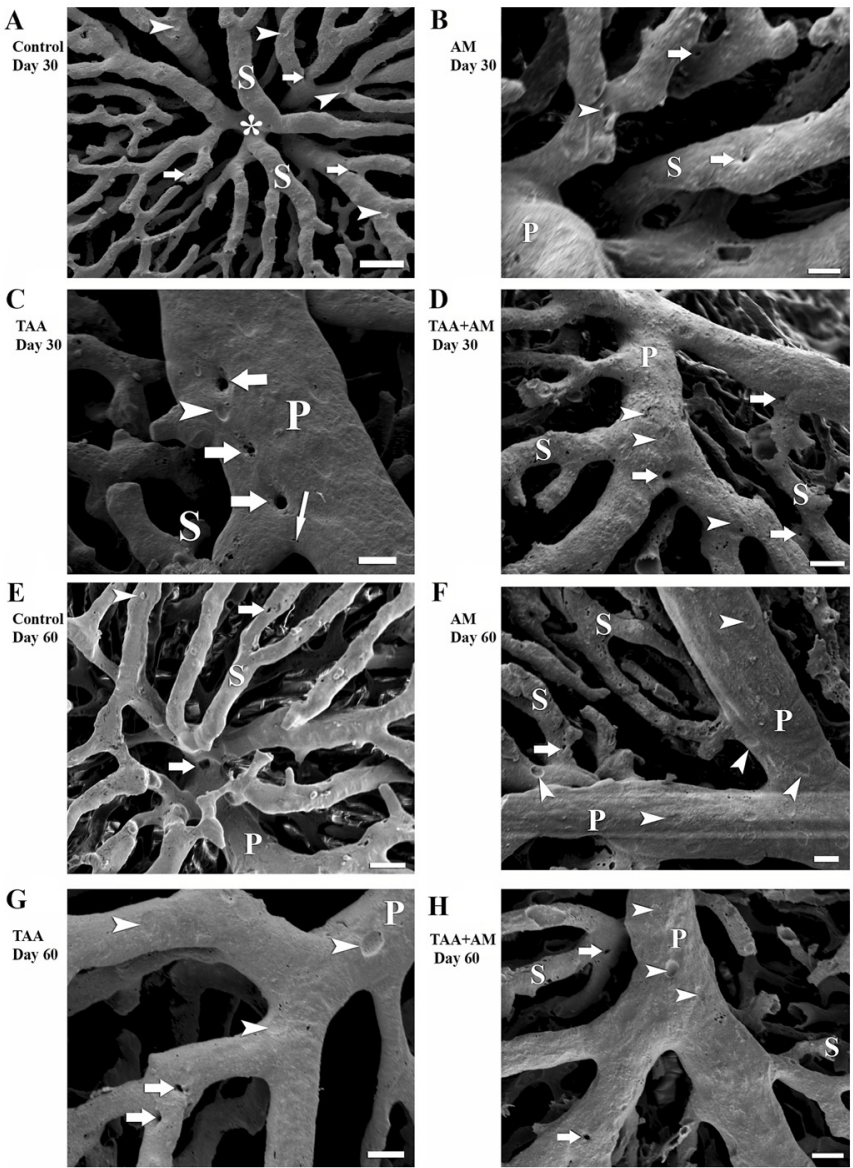

Figure 4. Higher magnifications of vascular corrosion casts of the liver Terminal hepatic venules are denoted by asterisks, tiny holes in vessels are denoted by arrows, imprints of endothelial cell nuclei are denoted by arrowheads, portal venules are denoted by a $\mathrm{P}$ and sinusoids are denoted by an S. (A-D) Higher magnification images of the casts shown in Fig. 2A-D (30 days of treatment). (E-H) Higher magnification images of the casts shown in Fig. 3A-D (60 days of treatment). Scale bar, $10 \mu \mathrm{m}$. (A) IA in control rats manifests as tiny holes (arrows) in the pericentral sinusoids. (B) Sinusoidal IA is present in the AM treated livers (arrows). (C) TAA treatment reveals rows of tiny holes in the portal vessels near their branching point (thin arrow). (D) IA at the branching angle of portal venules and sinusoids of the TAA+AM treated livers. (E) Tiny holes at branching points between the portal venules and sinusoids in the control liver. (F) Sinusoidal IA is also present in AM treated livers. (G) TAA treatment reveals the subsequent remodeling of the branching pattern of portal vessels. $(\mathrm{H})$ At the branching angle of portal venules and sinusoids of the TAA+AM treated livers, IA was also observed. Endothelial cell nuclei imprints (arrowheads) are clearly visible in panels A-F. IA, intussusceptive angiogenesis; AM, $\alpha$-mangostin; TAA, thioacetamide.

fibrosis was prevalent (Fig. 7H). Fibrous tissue formation in the periportal areas differed from that in the perivenular areas (Fig. 8C). This finding is consistent with the spaces that were observed around the terminal portal venules in the VCCs of the livers of rats treated with TAA for 60 days. The periportal structures and perivenular areas in the livers of rats treated with TAA+AM for 60 days were better preserved and contained less fibrotic tissue than livers treated with TAA only (Fig. 8D).

After both day 30 and day 60, there was no fibrosis in the control and AM-treated rats. In rats treated with TAA for 30 days, collagen fibers had expanded into several portal areas, whereas distinct bridging fibrosis (portal to portal or portal to central area) had developed after 60 days of TAA treatment. Fibrosis was significantly decreased in TAA+AM-treated rats
Table III. Ishak scores of liver sections in the treated rats ${ }^{\mathrm{a}}$.

\begin{tabular}{lcccc}
\hline & \multicolumn{4}{c}{ Groups } \\
\cline { 2 - 5 } Ishak score & Control & AM & TAA & TAA+AM \\
\hline Day 30 & $0.0 \pm 0.0$ & $0.0 \pm 0.00$ & $3.0 \pm 0.0^{\mathrm{b}}$ & $1.25 \pm 0.25^{\mathrm{c}}$ \\
Day 60 & $0.0 \pm 0.0$ & $0.0 \pm 0.00$ & $4.25 \pm 0.25^{\mathrm{b}, \mathrm{d}}$ & $1.75 \pm 0.25^{\mathrm{c}, \mathrm{d}}$
\end{tabular}

a Data are presented as the mean \pm standard deviation; ${ }^{\mathrm{b}} \mathrm{P}<0.0001$ vs. respective Control group; ${ }^{\mathrm{c}} \mathrm{P}<0.001$ vs. respective TAA group; ${ }^{\mathrm{P}} \mathrm{P}<0.001$, significant difference between day 30 and day 60 according to 2-way ANOVA with Bonferroni's corrections. AM, $\alpha$-mangostin; TAA, thioacetamide.

compared with the TAA-treated rats after 30 and 60 days of treatment (Table III).

$3 D$ morphometry. At day 30 of the experiment, the terminal portal venules and the pericentral sinusoids did not differ between the controls and any of the experimental groups. However, the diameter of the periportal sinusoids was significantly smaller in the TAA+AM-treated rats compared with the control or AM-treated rats (Fig. 9).

At day 60 of the experiment, none of the treatments had affected the diameter of the portal venules. However, TAA-treatment decreased the diameter of the periportal sinusoids and increased the diameter of the pericentral sinusoids significantly. Although AM treatment itself did not affect the diameter of the pericentral or periportal sinusoids, it tended to restore the diameter of the periportal venules to control values when added to the TAA treatment, although this effect was not significant. The TAA+AM treatment did however, further increase the diameter of the pericentral sinusoids (Fig. 10). At day 30 of the experiment, the branching angles between portal venules and sinusoids were acute and similar in all groups. At day 60 of the experiment, the branching angles between the hepatic portal venules and sinusoids were significantly different between the AM-treated groups compared with the TAA or TAA+AM-treated groups (Fig. 11). The representative anaglyphic red-green images of 3D morphometry of the branching angle between portal venules and sinusoids at day 30 and 60 in each treatment group are displayed in Fig. 12.

In summary, 3D morphometry confirmed that terminal portal venules were not affected in any of the groups. Pericentral sinusoids became wider in the TAA-treated rats during the second month of toxin administration, particularly if AM was added to the TAA treatment. Periportal sinusoids, by contrast, became smaller in the second month of toxin treatment. This effect was already visible after 1 month if AM was present in the treatment mix.

\section{Discussion}

In the present study, it was demonstrated that AM preserved sinusoidal microvascular architecture and ameliorated TAA-induced hepatocellular injuries at day 60 , but the effects were not significant after 30 days of treatment. The cause of this beneficial effect was likely the inhibition of fibrosis, which 

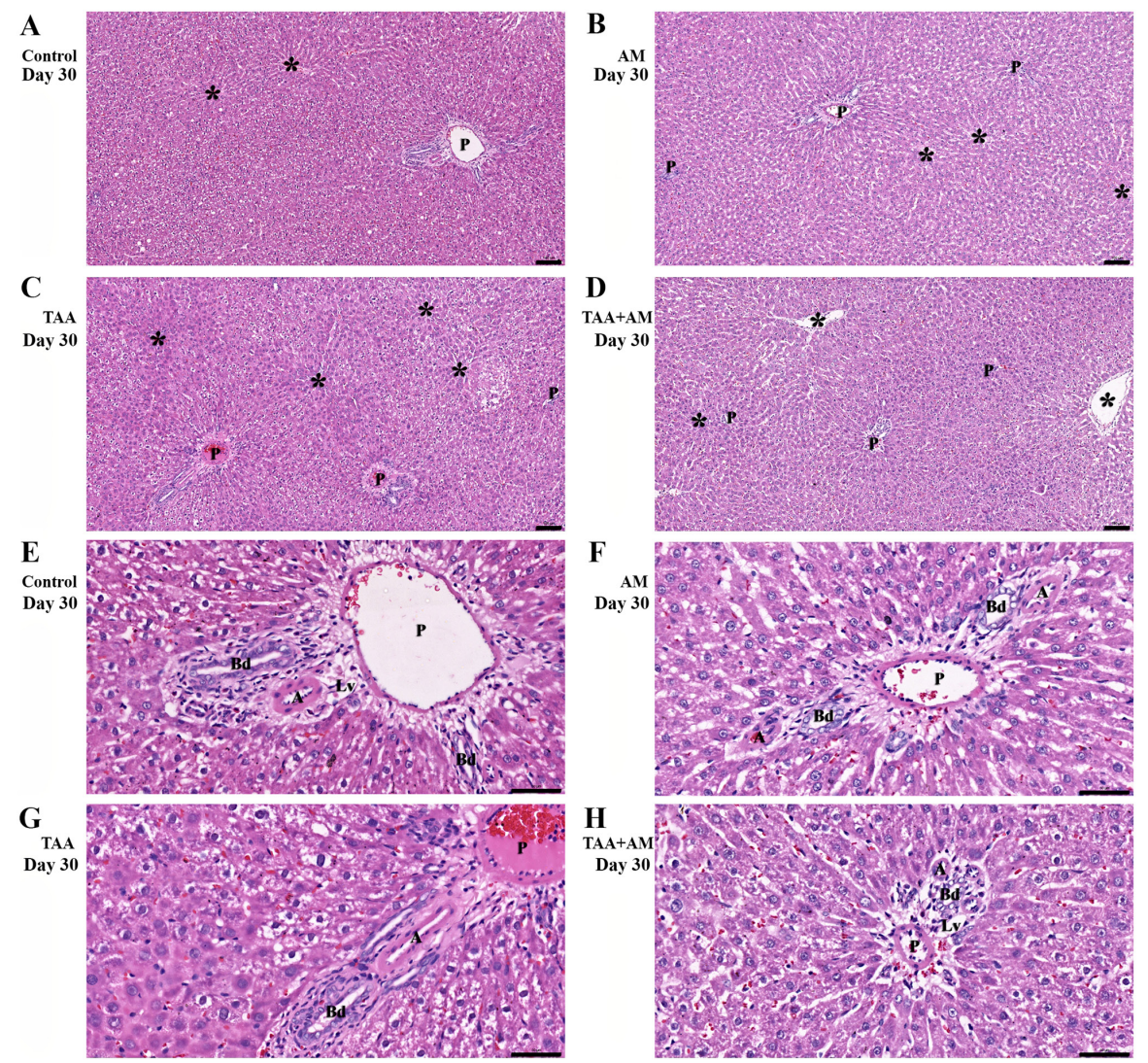

Figure 5. Histomorphology of rat livers after 30 days of treatment. Asterisks mark terminal hepatic venules. (A) Control and (B) AM-treated rats, with hepatic cords and intact portal structures. (C) Acute hepatocellular injury with periportal and perivenular inflammation was observed in the TAA-treated rats (D) perivenular hepatocyte injury and intact portal structures in the TAA+AM-treated rats. Scale bar, $100 \mu \mathrm{m}$. An intact portal tract structure was observed in the (E) control and (F) AM-treated rats. (G) Periportal and perivenular hepatocyte injury was observed in the TAA-treated rats. (H) Attenuation of periportal hepatocyte injury in the TAA and AM-treated rats. Panels E-H are higher magnifications of panels A-D, respectively. Scale bar, $50 \mu \mathrm{m}$. A, hepatic arteries; Bd, bile ducts; Lv, lymphatic vessels; P, portal venules; AM, $\alpha$-mangostin; TAA, thioacetamide.
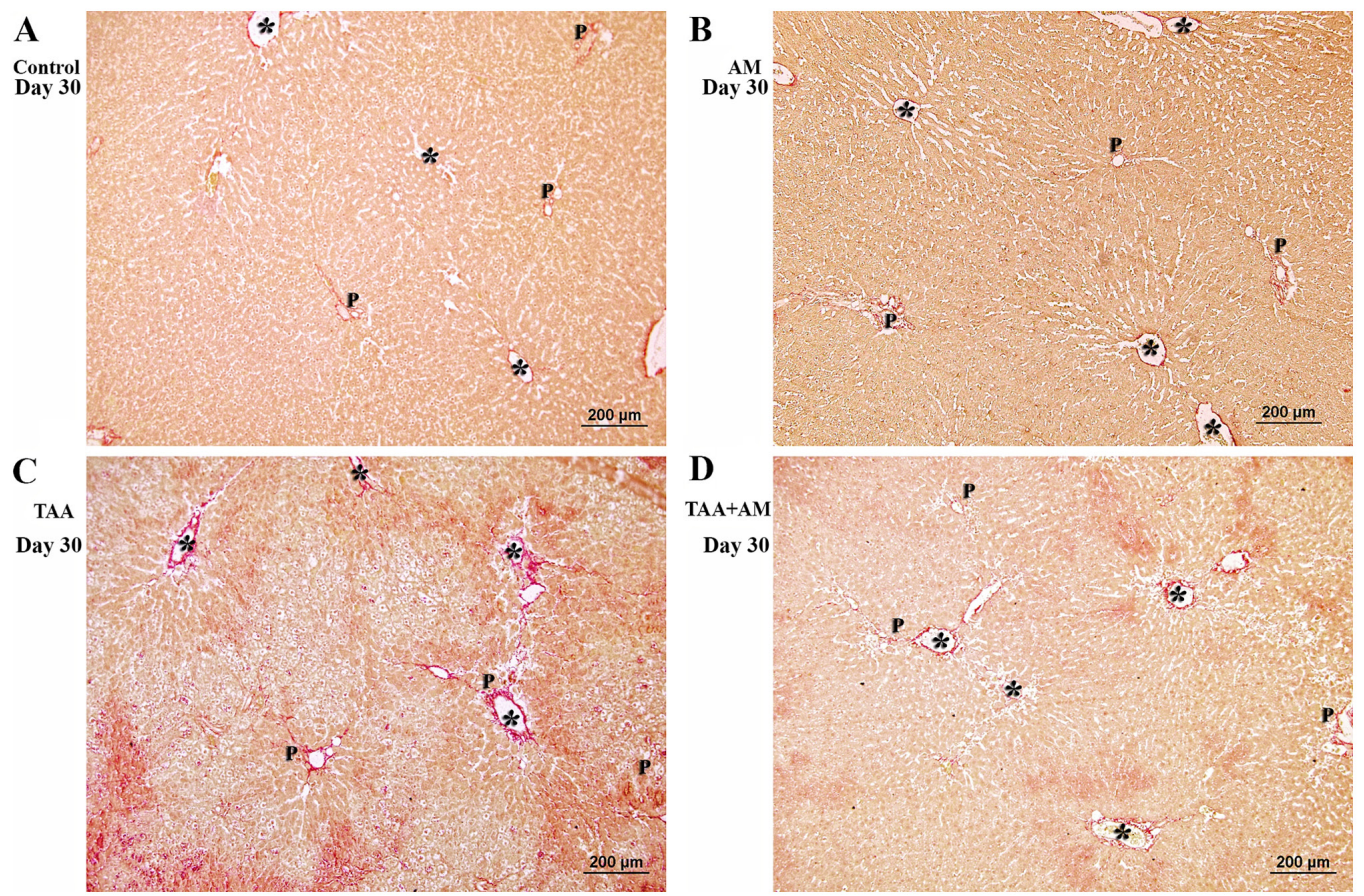

Figure 6. Collagen content and distribution in the rat livers after 30 days of treatment. Asterisks mark the terminal hepatic venules, and portal venules are defined by a P. Scale bar, $200 \mu \mathrm{m}$. The red color indicates the presence of collagen fibers, and the intensity of staining reflects the density of collagen fibers. (A) Control and (B) AM-treated rats exhibited hepatic cords and intact portal structures. (C) Acute hepatocellular injury with noticeable periportal and perivenular fibrosis was observed in the TAA-treated rats. (D) Addition of AM to the TAA treatment preserved portal structures and limited hepatocyte injury and inflammatory changes. AM, $\alpha$-mangostin; TAA, thioacetamide. 

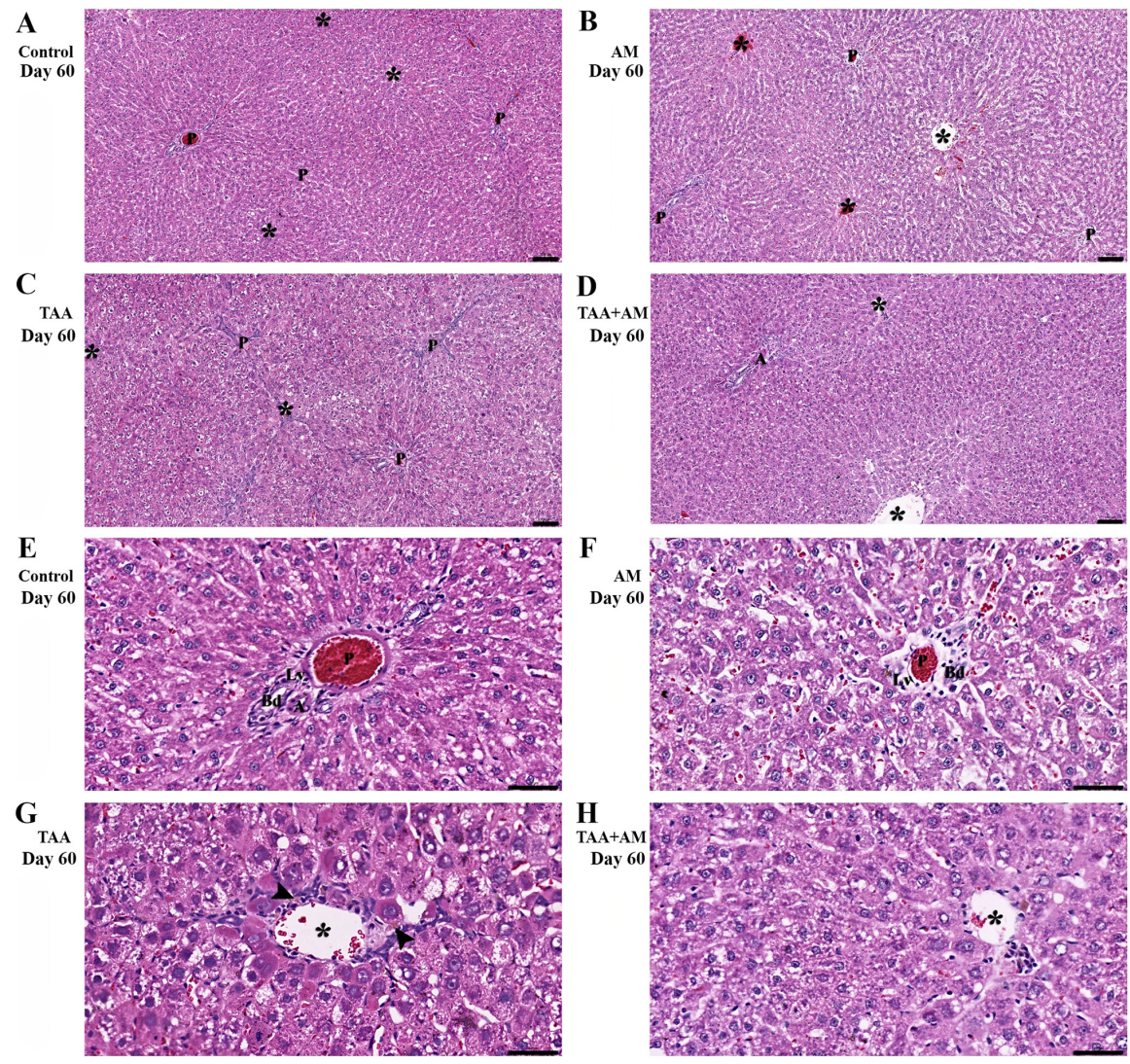

Figure 7. Histomorphology of the rat livers after 60 days of treatment. Terminal hepatic venules are marked by asterisks, whereas the arrowheads mark steatosis and cholestasis. (A, B, E and F) Show normal hepatic cords and intact portal structures in the control and AM-treated rats. (C) Periportal fibrosis and perivenular formation of fibrous tissue (arrow) was observed in the TAA-treated rats. (D) Perivenular fibrosis was also observed in the rats treated with both TAA and AM Scale bar, $100 \mu \mathrm{m}$. (G) Periportal microvesicular steatosis, cholestasis and fibrosis, and necroinflammatory was observed in the TAA-treated rats. (H) Attenuation of the perivenular fibrosis, as well as absent steatosis and cholestasis was observed in the rats treated with both TAA and AM. Panels E-H are higher magnifications of panels A-D, respectively. Scale bar, $50 \mu \mathrm{m}$. A, hepatic arteries; Bd, bile ducts; LV, lymphatic vessels; P, portal venules; AM, $\alpha$-mangostin; TAA, thioacetamide.
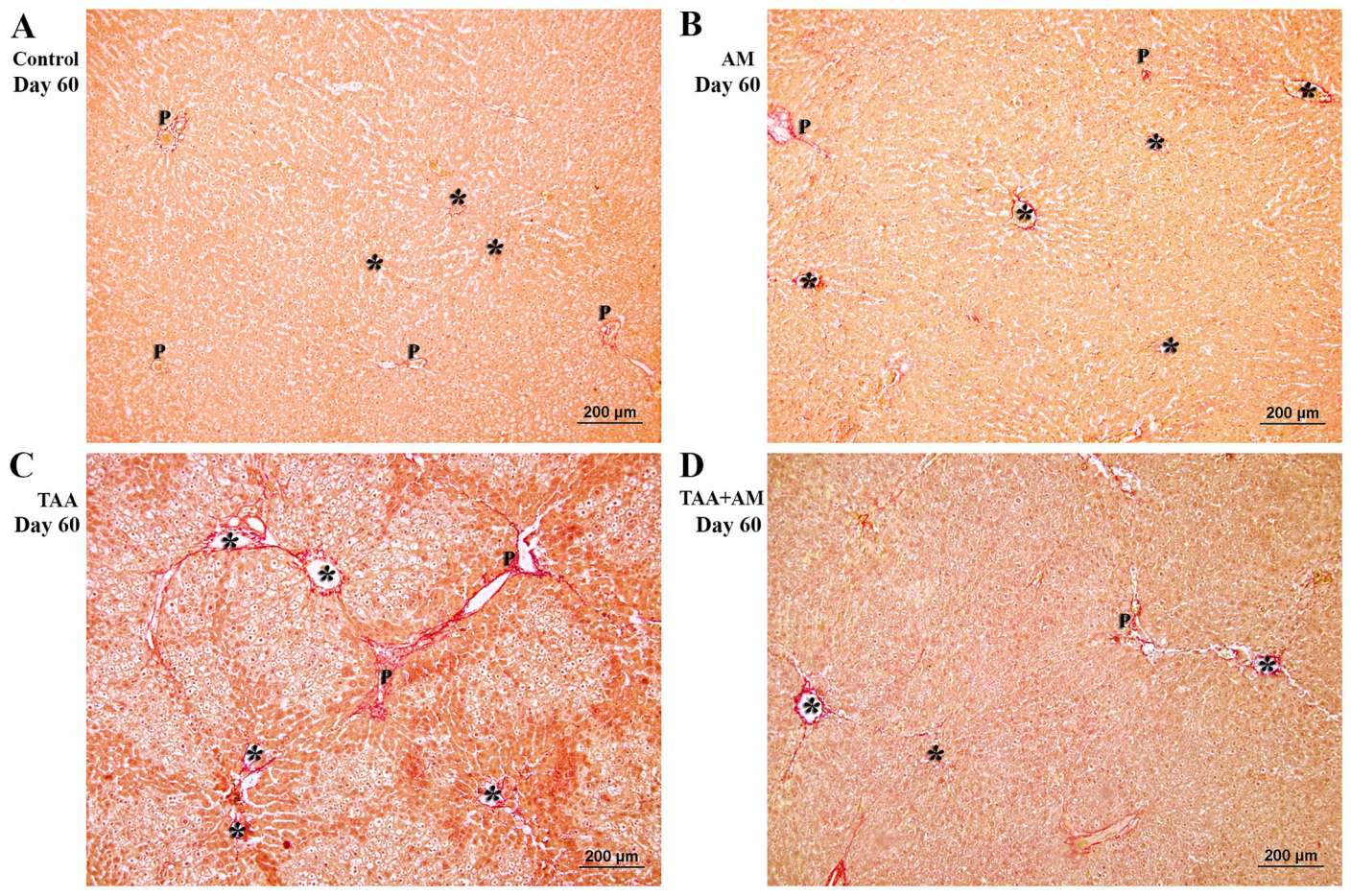

Figure 8. Sirius red staining of rat livers after 60 days of treatment. Asterisks mark terminal hepatic venules, and portal venules are denoted by a P. Scale bar, $20 \mu \mathrm{m}$. (A and B) Normal hepatic cords and intact portal structures were observed in the control and AM-treated rats. (C) Periportal and perivenular fibrosis was observed in the TAA-treated rats. (D) Compared with TAA treatment alone, additional treatment with AM reduced the development of fibrous tissue and preserved the architecture of the periportal and perivenular areas. AM, $\alpha$-mangostin; TAA, thioacetamide. 

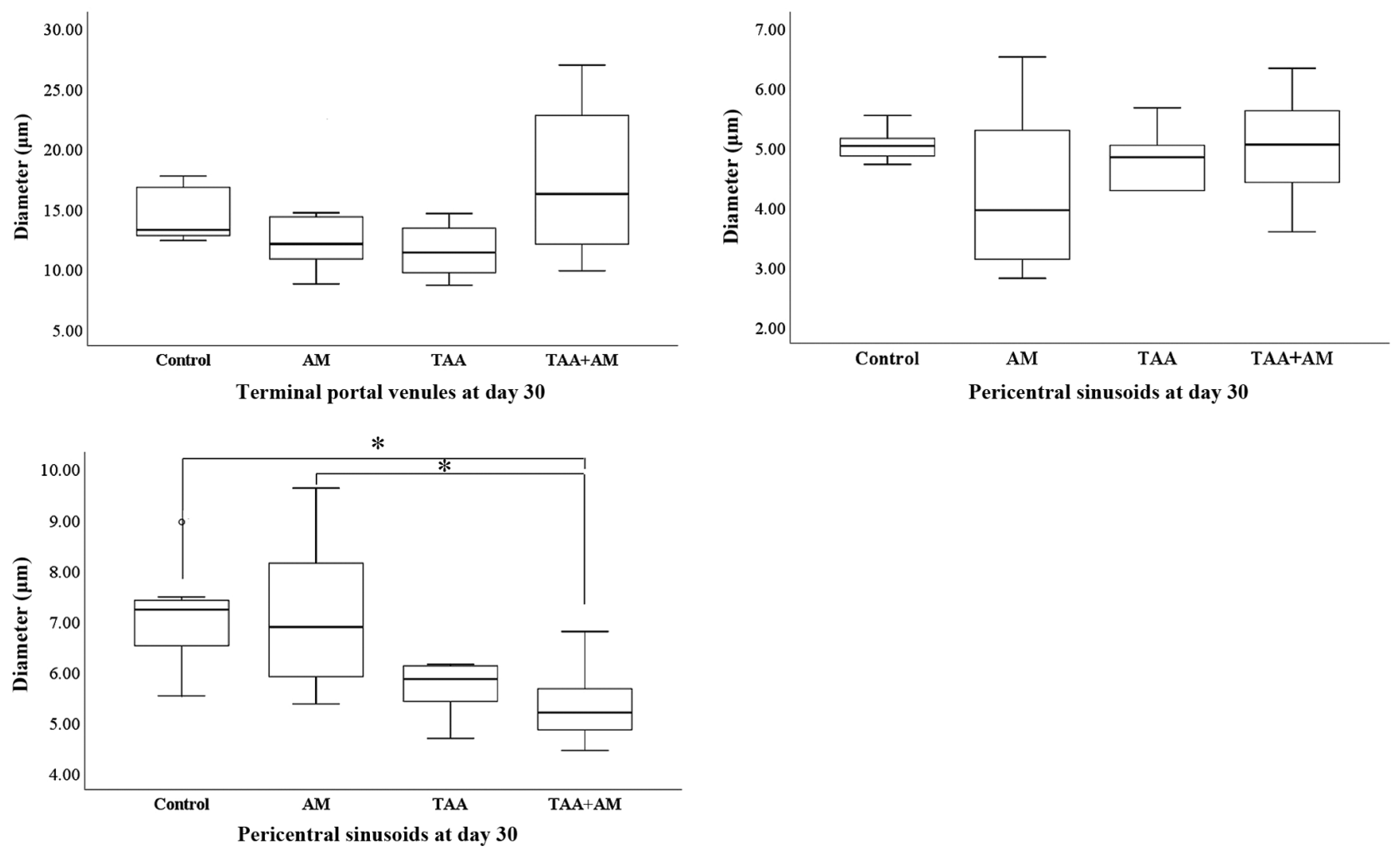

Figure 9. Diameter (in $\mu \mathrm{m}$ ) of hepatic vessels after 30 days of treatment, as calculated by 3D morphometry. Diameters are expressed as boxplots, with the median, lower and upper quartiles, and minimum and maximum values shown. "P<0.05. TAA, thioacetamide; AM, $\alpha$-mangostin.
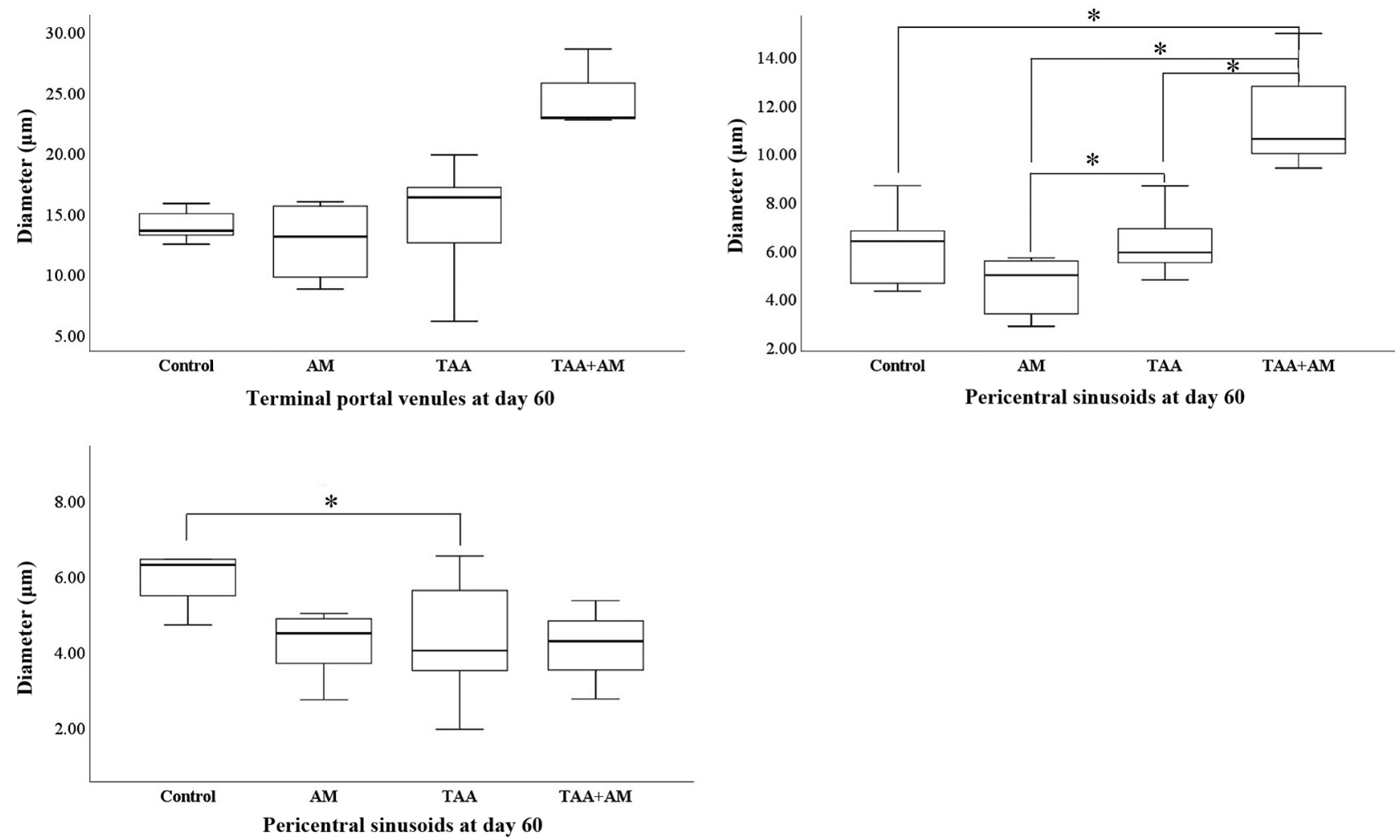

Figure 10. Diameter (in $\mu \mathrm{m}$ ) of hepatic vessels after 60 days of treatment, as calculated by 3D morphometry. Diameters are expressed as boxplots, with the median, lower and upper quartiles, and minimum and maximum values shown. ${ }^{*} \mathrm{P}<0.05$. TAA, thioacetamide; AM, $\alpha$-mangostin.

lead to preservation of periportal structures and a delay in the formation of periportal and pericentral fibrosis.
AM may induce morbidity and mortality in animals with increased dosages (55-57). AM induced mortality after $72 \mathrm{~h}$ of 

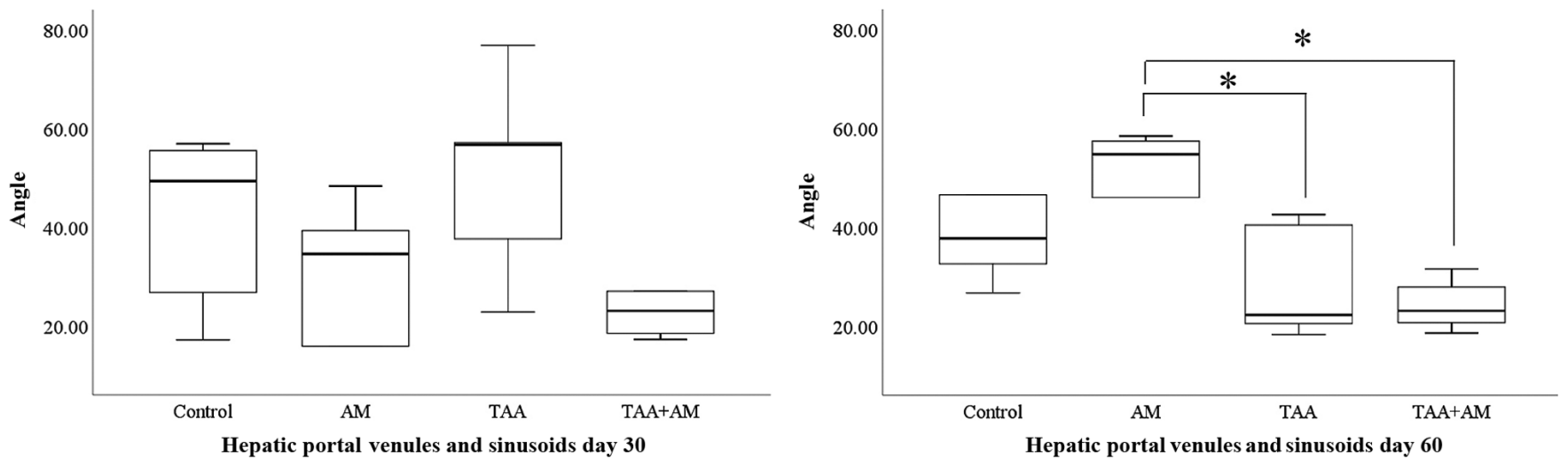

Figure 11. Branching angles of hepatic vessels after 30 (left) or 60 days of treatment (right), as calculated by 3D morphometry. Diameters are expressed as boxplots, with the median, lower and upper quartiles, and minimum and maximum values shown. "P<0.05. TAA, thioacetamide; AM, $\alpha$-mangostin.
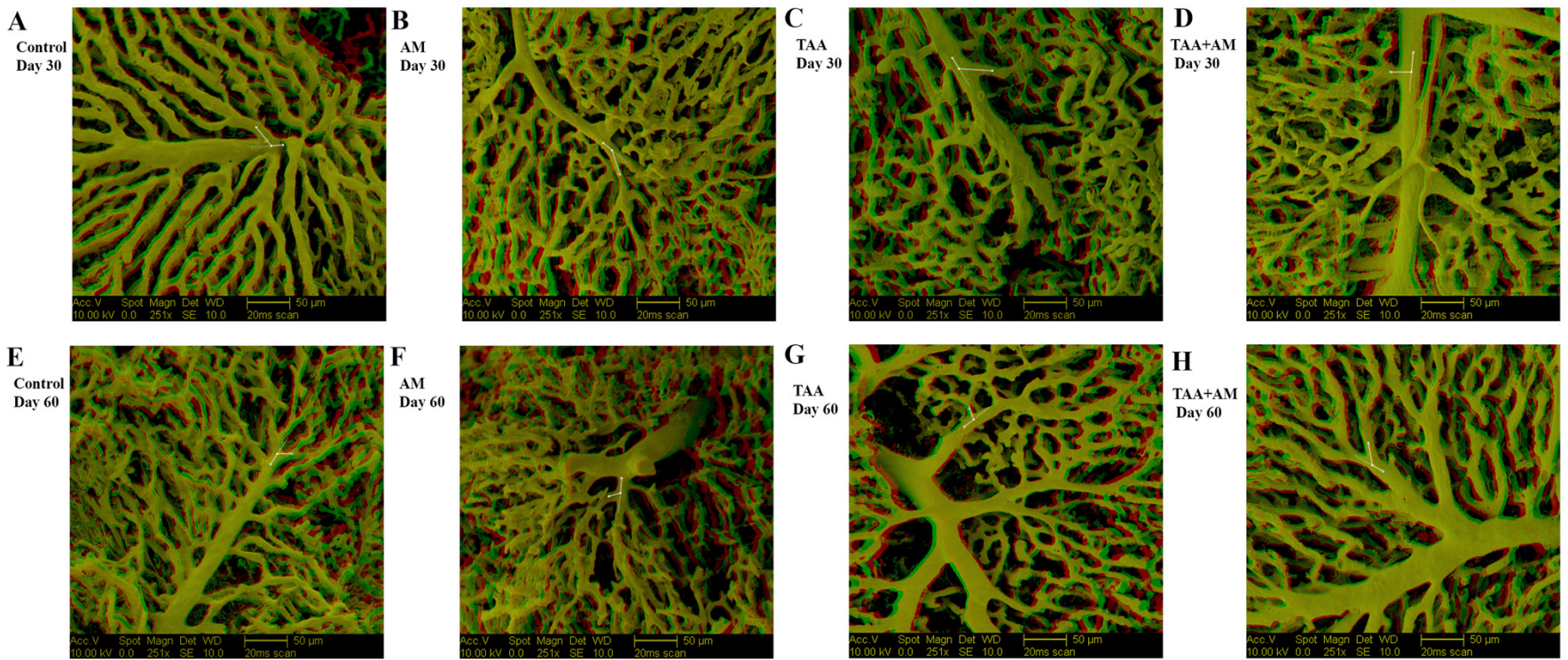

Figure 12. Representative anaglyphic red-green images of the 3D morphometry of the branching angle between portal venules and sinusoids. (A) Control, (B) AM, (C) TAA and (D) TAA+AM-treated rats after 30 days of treatment. (E) Control, (F) AM, (G) TAA and (H) TAA+AM-treated rats after 60 days of treatment. Red/green 3D glasses are required to view the 3D images. AM, $\alpha$-mangostin; TAA, thioacetamide.

intraperitoneal administration with a $50 \%$ lethal concentration of $150 \mathrm{mg} / \mathrm{kg}$ in a mouse model (57). To minimize the use and potentially adverse effects of AM, a dosage of TAA and AM that was $75 \%$ of that administered by Poonkhum et al (46) was used. In this previous study, TAA was administered at $200 \mathrm{mg} / \mathrm{kg} \mathrm{BW}$ and $\mathrm{AM}$ at $100 \mathrm{mg} / \mathrm{kg}$ BW (intraperitoneally), where the AM dose was 20x higher than in a study by Rodniem et al (45), where TAA was also administered at $200 \mathrm{mg} / \mathrm{kg} \mathrm{BW}$, but AM was administered only at $5 \mathrm{mg} / \mathrm{kg} \mathrm{BW}$ intraperitoneally. Thus, a 15 -fold higher AM concentration was used comparted with the study by Rodniem et al (45). In a pilot study, it was observed that treatment with AM intraperitoneally at $75 \mathrm{mg} / \mathrm{kg}$ BW did improve the blood vessel architecture in fibrotic liver without visible effects (data not shown). AM was clearly effective when $75 \mathrm{mg} / \mathrm{kg}$ BW was administered twice weekly. The primary effect of AM appeared to be an anti-fibrotic effect, as it showed anti-fibrogenic action in histological sections. Anti-fibrotic effects of AM preserved the vascular architecture under pro-oxidative conditions, such as TAA treatment. These findings underscore earlier studies that demonstrated that AM lowers the liver area occupied by type I collagen (46). At a dose of $100 \mathrm{mg} / \mathrm{kg}$ BW twice weekly, AM also reduced the risk of liver fibrosis through a decrease in p53 expression when examining induction of cirrhosis by TAA (58). Even a low dose of AM (5 mg/kg BW) prevented TAA from inducing hepatocyte damage based on the circulating hepatic enzyme concentrations and fibrotic changes in the liver (45). Relatively little information exists regarding the pharmacokinetics and pharmacodynamics of AM in rats, as only a few dosages and routes or intervals of administration have been studied previously (45,59-62). Further experiments along these lines are therefore warranted to determine the optimal anti-fibrogenic and anti-angiogenetic outcomes.

In the present study, it was shown that TAA-induced fibrosis at $150 \mathrm{mg} / \mathrm{kg}$ BW when administered 3 times weekly, and this caused tissue damage in the liver. In support of these findings, a previous study demonstrated that liver sinusoidal endothelial cell differentiation activated hepatic stellate cells 
and the associated fibrotic processes (63), which resulted in perivascular fibrosis (such as periportal and perivenular fibrosis), and this finally led to cirrhosis. A short-term low dose of TAA (50 mg/kg BW) can induce inflammation (64). TAA is metabolized by cytochrome P4502E1 into thioacetamides sulfoxide and thioacetamide-S, S-dioxide (65). These metabolites, whether they are further oxidized or not, form species that are toxic to hepatocytes $(66,67)$.

IA is a relatively more recently discovered novel means of blood vessel formation and provides a mechanism for the expansion of an existing microvascular network and vascular branch remodeling in both normal and pathological conditions (68). The presence of tiny holes with a diameter of $2-5 \mu \mathrm{m}$, which indicate signs of IA, are identifiable by microvascular corrosion casting and SEM. Fibrotic livers exhibit growth of numerous vessels through IA. The corrosion casts confirmed these data, showing the presence of numerous tiny holes within the hepatic vessels of fibrotic livers. It is speculated that the greater degree of fibrosis may contribute to the relative frequency of IA observed. Thus, microvascular alterations by IA may be a pivotal pathogenetic mechanisms in the progression of fibrosis. Interestingly, a recent study showed that IA was observed in the lungs of patients with COVID-19 and also in the lungs of patients with influenza (69). It would therefore be tempting to speculate that AM may exert anti-angiogenetic activity on continuous endothelium lined intrahepatic vessels, and this may be the result of diminished IA processes.

The progression of hepatocyte injuries is associated with intrahepatic angiogenesis and fibrosis, which ultimately leads to cirrhosis. The results showing that AM preserves the hepatic microvascular pattern, periportal structure and perivenular sinusoids underscores the hepatoprotective effect of AM on liver fibrosis. AM extracts, therefore, appear to exert a mitigating effect on liver fibrosis and angiogenesis. Further studies should address the mechanism underlying the anti-angiogenic and anti-fibrogenic effects of AM on intrahepatic vessels and sinusoids.

\section{Acknowledgements}

We would like to thank Dr Terdsak Yano (Department of Food Animal Clinic) and Dr Kannika Na Lampang (Department of Veterinary Biosciences and Public Health, Faculty of Veterinary Medicine, Chiang Mai University) for their assistance with the statistical analysis; Associate Professor Primchanien Mongkarndi (Department of Microbiology, Faculty of Pharmacy, Mahidol University) for assisting with $\alpha$-Mangostin extraction; Professor Wouter H. Lamers (Department of Anatomy and Embryology, Maastricht University) for manuscript corrections, and Associate Professor Korakot Nganvongpanit (Department of Veterinary Biosciences and Public Health, Faculty of Veterinary Medicine, Chiang Mai University) for the valuable comments provided.

\section{Funding}

This study was supported by the Faculty of Veterinary Medicine, Chiang Mai University (grant no. R000009358) and Ernst-Mach-Stipendien (Ernst-Mach weltweit TSO; grant no. ICM-02001) Austrian Agency for International
Cooperation in Education and Research OeAD-GmbH, Center for international Cooperation and Mobility (ICM).

\section{Availability of data and materials}

The datasets used and/or analyzed during the present study are available from the corresponding author on reasonable request.

\section{Author's contributions}

WT and WP conceived and designed the study, and also performed the histological examination of the liver. AL assisted with the vascular corrosion casting technique and SEM and 3D morphometry, and qualitatively analyzed the vascular corrosion casts. WT performed the experiments, analyzed and interpreted the quantitative 3D morphometry data, and was a major contributor in writing the manuscript with support from WP. All authors have read and approved the final manuscript. WP and AL confirm the authenticity of all the raw data.

\section{Ethics approval and consent to participate}

All of the experiments were approved by the Institutional Animal Care and Use Committee at the Faculty of Veterinary Medicine, Chiang Mai University (approval no. A.20/2555)

\section{Patient consent for publication}

Not applicable.

\section{Competing interests}

The authors agree that they have no competing interests.

\section{References}

1. Aydın MM and Akçalı KC: Liver fibrosis. Turk J Gastroenterol 29: 14-21, 2018.

2. Parola M and Pinzani M: Liver fibrosis: Pathophysiology, pathogenetic targets and clinical issues. Mol Aspects Med 65: 37-55, 2019.

3. Vollmar B and Menger MD: The hepatic microcirculation: Mechanistic contributions and therapeutic targets in liver injury and repair. Physiol Rev 89: 1269-1339, 2009.

4. McCuskey RS: The hepatic microvascular system in health and its response to toxicants. Anat Rec (Hoboken) 291: 661-671, 2008.

5. Lee UE and Friedman SL: Mechanisms of hepatic fibrogenesis. Best Pract Res Clin Gastroenterol 25: 195-206, 2011.

6. Wallace K, Burt AD and Wright MC: Liver fibrosis. Biochem J 411: 1-18, 2008

7. Lamireau T, Desmoulière A, Bioulac-Sage P and Rosenbaum J: Mechanisms of hepatic fibrogenesis. Arch Pediatr 9: 392-405, 2002 (In French).

8. Makanya AN, Hlushchuk R and Djonov VG: Intussusceptive angiogenesis and its role in vascular morphogenesis, patterning, and remodeling. Angiogenesis 12: 113-123, 2009.

9. Carmeliet P and Jain RK: Molecular mechanisms and clinical applications of angiogenesis. Nature 473: 298-307, 2011

10. Caballería L, Pera G, Arteaga I, Rodríguez L, Alumà A, Morillas RM, de la Ossa N, Díaz A, Expósito C, Miranda D, et al: high prevalence of liver fibrosis among european adults with unknown liver disease: A population-based study. Clin Gastroenterol Hepatol 16: 1138-1145.e5, 2018.

11. Ginès P, Graupera I, Lammert F, Angeli P, Caballeria L, Krag A, Guha IN, Murad SD and Castera L: Screening for liver fibrosis in the general population: A call for action. Lancet Gastroenterol Hepatol 1: 256-260, 2016. 
12. Raghu C, Ekena J, Cullen JM, Webb CB and Trepanier LA Evaluation of potential serum biomarkers of hepatic fibrosis and necroinflammatory activity in dogs with liver disease. J Vet Intern Med 32: 1009-1018, 2018.

13. Eulenberg VM and Lidbury JA: Hepatic fibrosis in dogs. J Vet Intern Med 32: 26-41, 2018.

14. Watson P: Canine breed-specific hepatopathies. Vet Clin North Am Small Anim Pract 47: 665-682, 2017.

15. Verhoef JNC, Allen AL, Harding JCS and Al-Dissi AN Metallothionein expression in horses with chronic liver disease and its correlation with Ki-67 immunoreactivity. Vet Pathol 55: 703-710, 2018

16. Perricone G, Vangeli M and Belli LS: Treatment of patients with cirrhosis. N Engl J Med 375: 2103, 2016.

17. Li X, Zhu L, Wang B, Yuan M and Zhu R: Drugs and targets in fibrosis. Front Pharmacol 8: 855-855, 2017.

18. Kaur V, Kumar M, Kaur P, Kaur S, Singh AP and Kaur S: Hepatoprotective activity of Butea monosperma bark against thioacetamide-induced liver injury in rats. Biomed Pharmacother 89: 332-341, 2017.

19. Sukalingam K, Ganesan K and Xu B: Protective effect of aqueous extract from the leaves of Justicia tranquebariesis against thioacetamide-induced oxidative stress and hepatic fibrosis in rats. Antioxidants 7: 7, 2018.

20. Kyung EJ, Kim HB, Hwang ES, Lee S, Choi BK, Kim JW, Kim HJ, Lim SM, Kwon OI and Woo EJ: Evaluation of Hepatoprotective Effect of curcumin on liver cirrhosis using a combination of biochemical analysis and magnetic resonance-based electrical conductivity imaging. Mediators Inflamm 2018: 5491797, 2018.

21. Foti RS, Pearson JT, Rock DA, Wahlstrom JL and Wienkers LC: In vitro inhibition of multiple cytochrome P450 isoforms by xanthone derivatives from mangosteen extract. Drug Metab Dispos 37: 1848-1855, 2009.

22. Gopalakrishnan G, Banumathi B and Suresh G: Evaluation of the antifungal activity of natural xanthones from Garcinia mangostana and their synthetic derivatives. J Nat Prod 60: 519-524, 1997.

23. Obolskiy D, Pischel I, Siriwatanametanon N and Heinrich M: Garcinia mangostana L.: A phytochemical and pharmacological review. Phytother Res 23: 1047-1065, 2009.

24. Martínez A, Galano A and Vargas R: Free radical scavenger properties of $\alpha$-mangostin: Thermodynamics and kinetics of HAT and RAF mechanisms. J Phys Chem B 115: 12591-12598, 2011.

25. Buelna-Chontal M, Correa F, Hernández-Reséndiz S, Zazueta $C$ and Pedraza-Chaverri J: Protective effect of $\alpha$-mangostin on cardiac reperfusion damage by attenuation of oxidative stress. J Med Food 14: 1370-1374, 2011

26. Ngawhirunpat T, Opanasopi P, Sukma M, Sittisombut C, Kat $\mathrm{A}$ and Adachi I: Antioxidant, free radical-scavenging activity and cytotoxicity of different solvent extracts and their phenolic constituents from the fruit hull of mangosteen (Garcinia mangostana). Pharm Biol 48: 55-62, 2010.

27. Pedraza-Chaverrí J, Reyes-Fermín LM, Nolasco-Amaya EG Orozco-Ibarra M, Medina-Campos ON, González-Cuahutencos O, Rivero-Cruz I and Mata R: ROS scavenging capacity and neuroprotective effect of alpha-mangostin against 3-nitropropionic acid in cerebellar granule neurons. Exp Toxicol Pathol 61: 491-501, 2009.

28. Koh JJ, Qiu S, Zou H, Lakshminarayanan R, Li J, Zhou X, Tang C, Saraswathi P, Verma C, Tan DT, et al: Rapid bactericidal action of alpha-mangostin against MRSA as an outcome of membrane targeting. Biochim Biophys Acta 1828: 834-844, 2013.

29. Dharmaratne HR, Sakagami Y, Piyasena KG and Thevanesam V: Antibacterial activity of xanthones from Garcinia mangostana (L.) and their structure-activity relationship studies. Nat Prod Res 27: 938-941, 2013.

30. Liu SH,Lee LT, Hu NY, Huange KK, Shih YC, Munekazu I, Li JM, Chou TY, Wang WH and Chen TS: Effects of alpha-mangostin on the expression of anti-inflammatory genes in U937 cells. Chin Med 7: 19, 2012

31. Chen LG, Yang LL and Wang CC: Anti-inflammatory activity of mangostins from Garcinia mangostana. Food Chem Toxicol 46: 688-693, 2008

32. Chomnawang MT, Surassmo S, Nukoolkarn VS and Gritsanapan W: Effect of Garcinia mangostana on inflammation caused by Propionibacterium acnes. Fitoterapia 78: 401-408, 2007.

33. Chin YW, Shin E, Hwang BY and Lee MK: Antifibrotic constituents from Garcinia mangostana. Nat Prod Commun 6 : $1267-1268,2011$.

34. Wang JJ, Shi QH, Zhang W and Sanderson BJ: Anti-skin cancer properties of phenolic-rich extract from the pericarp of mangosteen (Garcinia mangostana Linn.). Food Chem Toxicol 50: 3004-3013, 2012.
35. Kurose H, Shibata MA, Iinuma M and Otsuki Y: Alterations in cell cycle and induction of apoptotic cell death in breast cancer cells treated with $\alpha$-mangostin extracted from mangosteen pericarp. J Biomed Biotechnol 2012: 672428, 2012.

36. Krajarng A, Nilwarankoon S, Suksamrarn S and Watanapokasin R: Antiproliferative effect of $\alpha$-mangostin on canine osteosarcoma cells. Res Vet Sci 93: 788-794, 2012.

37. Kaomongkolgit R: Alpha-mangostin suppresses MMP-2 and MMP-9 expression in head and neck squamous carcinoma cells. Odontology 101: 227-232, 2013.

38. Johnson JJ, Petiwala SM, Syed DN, Rasmussen JT, Adhami VM, Siddiqui IA, Kohl AM and Mukhtar H: $\alpha$-Mangostin, a xanthone from mangosteen fruit, promotes cell cycle arrest in prostate cancer and decreases xenograft tumor growth. Carcinogenesis 33: 413-419, 2012

39. Aisha AF, Abu-Salah KM, Ismail Z and Majid AM: alpha-Mangostin enhances betulinic acid cytotoxicity and inhibits cisplatin cytotoxicity on HCT 116 colorectal carcinoma cells. Molecules 17: 2939-2954, 2012.

40. Chao AC, Hsu YL, Liu CK and Kuo PL: $\alpha$-Mangostin, a dietary xanthone, induces autophagic cell death by activating the AMP-activated protein kinase pathway in glioblastoma cells. J Agric Food Chem 59: 2086-2096, 2011.

41. Shiozaki T, Fukai M, Hermawati E, Juliawaty LD, Syah YM, Hakim EH, Puthongking P, Suzuki T, Kinoshita K, Takahashi K, et al: Anti-angiogenic effect of alpha-mangostin. J Nat Med 67: 202-206. 2013

42. National Research Council Committee for the Update of the Guide for the Care and Use of Laboratory A: The National Academies Collection: Reports funded by National Institutes of Health. In: Guide for the Care and Use of Laboratory Animals. National Academies Press (US). National Academy of Sciences, Washington, DC, 2011.

43. Sattayasai J, Chaonapan P, Arkaravichie T, Soi-Ampornkul R, Junnu S, Charoensilp P, Samer J, Jantaravinid J, Masaratana P, Suktitipat B, et al: Protective effects of mangosteen extract on $\mathrm{H}_{2} \mathrm{O}_{2}$-induced cytotoxicity in $\mathrm{SK}-\mathrm{N}-\mathrm{SH}$ cells and scopolamine-induced memory impairment in mice. PLoS One 8: e85053, 2013

44. Moongkarndi P, Srisawat C, Saetun P, Jantaravinid J, Peerapittayamongkol C, Soi-ampornkul R, Junnu S, Sinchaikul S, Chen ST, Charoensilp P, et al: Protective effect of mangosteen extract against beta-amyloid-induced cytotoxicity, oxidative stress and altered proteome in SK-N-SH cells. J Proteome Res 9: 2076-2086, 2010

45. Rodniem S, Tiyao V, Nilbu-Nga C, Poonkhum R, Pongmayteegul S and Pradidarcheep W: Protective effect of alpha-mangostin on thioacetamide-induced liver fibrosis in rats as revealed by morpho-functional analysis. Histol Histopathol 34: 419-430, 2019.

46. Poonkhum R, Watanapokasin R and Pradidarcheep W: Protective effect of alpha-mangostin against type-I collagen formation in thioacetamide-induced cirrhotic rat. J Med Assoc Thai 95 (Suppl 12): S93-S98, 2012.

47. Lametschwandtner A, Lametschwandtner U and Weiger T: Scanning electron microscopy of vascular corrosion casts technique and applications: Updated review. Scanning Microsc 4: 889-940, discussion 941, 1990.

48. Lametschwandtner A, Miodonski A and Simonsberger P: On the prevention of specimen charging in scanning electron microscopy of vascular corrosion casts by attaching conductive bridges. Mikroskopie 36: 270-273, 1980.

49. Standish RA, Cholongitas E, Dhillon A, Burroughs AK and Dhillon AP: An appraisal of the histopathological assessment of liver fibrosis. Gut 55: 569-578, 2006.

50. Schumann G, Bonora R, Ceriotti F, Férard G, Ferrero CA, Franck PF, Gella FJ, Hoelzel W, Jørgensen PJ, Kanno T, et al; International Federation of Clinical Chemistry and Laboratory Medicine: IFCC primary reference procedures for the measurement of catalytic activity concentrations of enzymes at 37 degrees C. International Federation of Clinical Chemistry and Laboratory Medicine. Part 4. Reference procedure for the measurement of catalytic concentration of alanine aminotransferase. Clin Chem Lab Med 40: 718-724, 2002.

51. Schumann G, Bonora R, Ceriotti F, Férard G, Ferrero CA, Franck PF, Gella FJ, Hoelzel W, Jørgensen PJ, Kanno T, et al; International Federation of Clinical Chemistry and Laboratory Medicine: IFCC primary reference procedures for the measurement of catalytic activity concentrations of enzymes at 37 degrees C. International Federation of Clinical Chemistry and Laboratory Medicine. Part 5. Reference procedure for the measurement of catalytic concentration of aspartate aminotransferase. Clin Chem Lab Med 40: 725-733, 2002. 
52. Schumann G, Klauke R, Canalias F, Bossert-Reuther S, Franck PF, Gella FJ, Jørgensen PJ, Kang D, Lessinger JM, Panteghini M, et al: IFCC primary reference procedures for the measurement of catalytic activity concentrations of enzymes at $37^{\circ} \mathrm{C}$. Part 9: Reference procedure for the measurement of catalytic concentration of alkaline phosphatase International Federation of Clinical Chemistry and Laboratory Medicine (IFCC) Scientific Division, Committee on Reference Systems of Enzymes (C-RSE) (1)). Clin Chem Lab Med 49: 1439-1446, 2011

53. Minnich B and Lametschwandtner A: Lengths measurements in microvascular corrosion castings: Two-dimensional versus three-dimensional morphometry. Scanning 22: 173-177, 2000.

54. Minnich B, Leeb H, Bernroider EW and Lametschwandtner A: Three-dimensional morphometry in scanning electron microscopy: A technique for accurate dimensional and angular measurements of microstructures using stereopaired digitized images and digital image analysis. J Microsc 195: 23-33, 1999.

55. Do HTT and Cho J: Mangosteen pericarp and its bioactive xanthones: Potential therapeutic value in Alzheimer's disease, Parkinson's disease, and depression with pharmacokinetic and safety profiles. Int J Mol Sci 21: 21, 2020.

56. Kittipaspallop W, Taepavarapruk P, Chanchao C and Pimtong W: Acute toxicity and teratogenicity of $\alpha$-mangostin in zebrafish embryos. Exp Biol Med (Maywood) 243: 1212-1219, 2018.

57. Choi YH, Han SY, Kim YJ, Kim YM and Chin YW: Absorption, tissue distribution, tissue metabolism and safety of $\alpha$-mangostin in mangosteen extract using mouse models. Food Chem Toxicol 66: 140-146, 2014.

58. Supawadee S, Thanet S, Wisut P, Somneuk N, Sirinun N and Ramida W: Investigation of therapeutic effects of $\alpha$-mangostin on thioacetamide-induced cirrhosis in rats. J Med Assoc Thai 98 (Suppl 9): S91-S97, 2015.

59. Ghasemzadeh Rahbardar M, Razavi BM and Hosseinzadeh $H$ : Investigating the ameliorative effect of alpha-mangostin on development and existing pain in a rat model of neuropathic pain Phytother Res 34: 3211-3225, 2020.

60. Ibrahim MY, Hashim NM, Mariod AA, Mohan S, Abdulla MA, Abdelwahab SI and Arbab IA: $\alpha$-Mangostin from Garcinia mangostana Linn: An updated review of its pharmacological properties. Arab J Chem 9: 317-329, 2016.
61. Upegui Y, Robledo SM, Gil Romero JF, Quiñones W, Archbold R, Torres F, Escobar G, Nariño B and Echeverri F: In vivo Antimalarial Activity of $\alpha$-Mangostin and the New Xanthone ठ-Mangostin. Phytother Res 29: 1195-1201, 2015.

62. Petiwala SM, Li G, Ramaiya A, Kumar A, Gill RK, Saksena S and Johnson JJ: Pharmacokinetic characterization of mangosteen (Garcinia mangostana) fruit extract standardized to $\alpha$-mangostin in C57BL/6 mice. Nutr Res 34: 336-345, 2014.

63. Xie G, Wang X, Wang L, Wang L, Atkinson RD, Kanel GC, Gaarde WA and Deleve LD: Role of differentiation of liver sinusoidal endothelial cells in progression and regression of hepatic fibrosis in rats. Gastroenterology 142: 918-927.e6, 2012.

64. Schyman P, Printz RL, Estes SK, Boyd KL, Shiota M and Wallqvist A: Identification of the toxicity pathways associated with thioacetamide-induced injuries in rat liver and kidney. Front Pharmacol 9: 1272, 2018.

65. Porter WR and Neal RA: Metabolism of thioacetamide and thioacetamide S-oxide by rat liver microsomes. Drug Metab Dispos 6: 379-388, 1978.

66. Spira B and Raw I: The effect of thioacetamide on the activity and expression of cytosolic rat liver glutathione-S-transferase. Mol Cell Biochem 211: 103-110, 2000.

67. Dyroff MC and Neal RA: Studies of the mechanism of metabolism of thioacetamide s-oxide by rat liver microsomes. Mol Pharmacol 23: 219-227, 1983

68. Mentzer SJ and Konerding MA: Intussusceptive angiogenesis: Expansion and remodeling of microvascular networks. Angiogenesis 17: 499-509, 2014.

69. Ackermann M, Verleden SE, Kuehnel M, Haverich A, Welte T, Laenger F, Vanstapel A, Werlein C, Stark H, Tzankov A, et al: Pulmonary Vascular Endothelialitis, Thrombosis, and Angiogenesis in Covid-19. N Engl J Med 383: 120-128, 2020.

This work is licensed under a Creative Commons Attribution-NonCommercial-NoDerivatives 4.0 International (CC BY-NC-ND 4.0) License. 